\title{
Traço falciforme no Brasil: revisão da literatura e proposta de tecnologia de informação para orientação de profissionais da atenção primária
}

\section{Sickle cell trait in Brazil: literature review and information technology proposal for basic health providers' guidance}

\begin{abstract}
Alex Monteiro de Sousaํ. Francisco Ranilson Alves Silva².
1 Pediatra pelo Hospital Universitário Walter Cantídio (HUWC), Universidade Federal do Ceará (UFC), Residente de Hematologia e Hemoterapia Pediátrica do Hospital das Clínicas de Ribeirão Preto, Universidade de São Paulo (USP), São Paulo, Brasil. 2 Mestre em Pediatria pela Universidade Estadual do Ceará (UECE), Supervisor da Residência de Pediatria do Hospital Universitário Walter Cantídio (HUWC), Universidade Federal do Ceará (UFC), Fortaleza, Ceará, Brasil.
\end{abstract}

\section{RESUMO}

INTRODUÇÃO: doença falciforme é uma anemia hemolítica hereditária ocasionada pela formação de uma hemoglobina mutante (Hemoglobina S), que afoiça as hemácias. O traço falciforme nomeia a condição benigna e assintomática de portador, não configurando doença. Os profissionais de atenção básica devem ser orientados sobre o teste do pezinho para hemoglobinopatias, e avaliar a necessidade de encaminhamento ao especialista. OBJETIVOS: elaborar e emitir boletim informativo e fluxograma de atendimento afim de determinar a conduta frente à criança com traço falciforme na atenção primária. METODOLOGIA: trabalho de revisão bibliográfica descritiva, documental, realizado nos web sites: scielo.com.br, bvsms.saude.gov.br, uptodate. com. DISCUSSÃO: no Brasil, acredita-se que a prevalência de traço falciforme seja de 27/1000 nascimentos, chegando até 6\% de toda população negra, configurando um sério problema de saúde pública. Estudos demonstraram que conhecimento e confiança dos profissionais na condução destes casos podem aumentar significativamente com estratégias educacionais simples. CONCLUSÃO: frente à alta prevalência de traço falciforme no país, e diante da oneração ao já sobrecarregado sistema de saúde, verifica-se a necessidade de orientação dos profissionais de atenção básica para o atendimento da criança com traço falciforme.

Palavras-chave: Doença falciforme. Traço falciforme. Teste do pezinho. Prevalência.

\section{ABSTRACT}

INTRODUCTION: sickle cell disease is an inherited hemolytic anemia due to a genetic mutation that distorts erythrocytes (Hemoglobin S). Sickle cell trait is an asymptomatic benign heterozygosis carrier condition. From the results of hemoglobinopathies neonatal screening, primary care providers have to judge when refer to a specialized approach or to follow up at basic health assistance. OBJECTIVES: conceive an Instructional Report and an Attending Flowchart as educational strategies guiding basic health assistants on hemoglobinopathies neonatal screening. METHODOLOGY: bibliographic descriptive, documental, review essay researching science websites data, scielo.com.br, bvsms.saude.gov.br, uptodate.com, also pediatrics textbooks and conceiving an Instructional Report and a Sickle Cell Trait Attending Flowchart. DISCUSSION: in Brazil, sickle cell trait can be found in $27 / 1000$ births, and within african-american descendants' prevalence is $1-6 \%$, consisting on a serious public health assistance problem. Concerning to primary care providers' qualification, some articles reveal that knowledge and confidence on their management could be improved with simple educational interventions. CONCLUSION: forwards sickle cell trait high prevalence in Brazil and overload of the strained health public assistance, it's stablished the prominence of primary care providers' accomplishments in sickle cell trait.

Keywords: Sickle cell disease. Sickle cell trait. Neonatal screening. Prevalence.

Autor correspondente: Alex Monteiro de Sousa, Rua Professor Alves de Godoi, 95, Jardim Nova Aliança, Ribeirão Preto, São Paulo. CEP: 14.026-592.Telefone: +55 85 99939-6975. E-mail: emaildoalexmonteiro@gmail.com

Conflito de interesses: Não há qualquer conflito de interesses por parte de qualquer um dos autores.

Recebido em: 06 Abr 2016; Revisado em: 05 Set 2016; Aceito em: 07 Nov 2016. 


\section{INTRODUÇÃO}

Doença falciforme é uma anemia hemolítica hereditária autossômica recessiva ocasionada pela formação de uma hemoglobina mutante (Hemoglobina S), que provoca distorção nas hemácias, dando-lhes o característico formato de foice ou meia-lua; e pode ser homozigótica (HbSS), chamada anemia falciforme, ou em heterozigose por associação com outro gene mutante da cadeia beta (variante S/Beta-Talassemia, $\mathrm{SC}$, SD e outras), chamada doença falciforme. Fenômenos vasoclusivos e hemólise levando à anemia são os principais marcos da doença falciforme, com episódios recorrentes de dor aguda, que levam a um grande número de atendimentos de emergência., ${ }^{1,2}$

O traço falciforme nomeia a condição de heterozigose do gene mutante falcêmico, em que o outro alelo é normal (HbAS), condição benigna e assintomática em que o indivíduo é portador de um gene mutante, mas não desenvolve a doença, não necessitando de acompanhamento especializado. Sua maior importância se encontra no aconselhamento genético, devido à chance de os descendentes nascerem com doença falciforme. ${ }^{1,3}$

Acredita-se que cerca de 250.000 crianças nasçam por ano com anemia falciforme ao redor do mundo, e cerca de 3.500 apenas no Brasil, onde a prevalência de anemia falciforme é de até 1/1000 nascimentos e a de traço falciforme, de 27/1000 nascimentos, principalmente nos estados do Nordeste e Sudeste, onde há maior número de descendentes africanos. ${ }^{3,4}$

A triagem neonatal para hemoglobinopatias faz parte do teste do pezinho e geralmente é primeiramente avaliada pelos profisisonais da atenção básica e pode indicar os seguintes resultados: FA (hemoglobina $\mathrm{F}$ e hemoglobina $\mathrm{A}$ ), resultado normal; FAS (hemoglobina F, hemoglobina A e hemoglobina S) representa o estado de portador, o traço falciforme; resultados FS (hemoglobina F e hemoglobina S), positivo para doença falciforme, devendo ser encaminhados ao especialista e realizar exames laboratoriais confirmatórios após o sexto mês de vida, quando há modificação do perfil hemoglobínico do padrão fetal para o padrão adulto, além de ser realizado o estudo familiar. Além destes, outros resultados indicando traços de outras hemoglobinopatias ou outros padrões de doença falciforme, quando se associa a outras mutações, podem ser diagnosticados e devem ser avaliados. ${ }^{5}$

Quando diagnosticada precocemente, o acompanhamento multiprofissional é iniciado ainda nos primeiros meses de vida, promovendo a realização de imunizações e antibioticoprofilaxia, educação em saúde direcionada ao paciente e aos familiares sobre os principais sintomas e a história natural da doença. Quando um resultado positivo não for avaliado precocemente, o diagnóstico somente será realizado quando do início dos sintomas ou da recorrência das manifestações clínicas, aumentando a chance de ocorrência de sequelas e complicações, levando a um aumento da morbimortalidade, além de fatores como estresse familiar pela ocorrência de uma doença crônica hereditária, tempo prolongado de espera até a consulta com o especialista, despesas e absenteísmo dos pais e oneração ao serviço público.

\section{OBJETIVOS}

Elaborar um fluxograma de conduta e um boletim informativo sobre a interpretação da triagem para hemoglobinopatias do teste do pezinho voltado para os profissionais de atenção básica.

\section{METODOLOGIA}

Trabalho de revisão bibliográfica descritiva, documental, realizada através de pesquisa em periódicos científicos e tratados de pediatria, utilizando os descritores "teste do pezinho", "traço falciforme", "doença falciforme" e "prevalência", além dos termos correspondentes em inglês "neonatal screening", "sickle cell trait", "sickle cell disease", "prevalence".

Foram inicialmente selecionados 27 artigos e 2 capítulos de livros, dos quais, por fim, foram inclusos dez artigos da base de dados Uptodate (uptodate.com), sete artigos do Scielo (scielo.org), três artigos da pubmed (ncbi.nlm.nih. gov/pubmed/) e mais dois artigos e um capítulo de livro de universidades/instituições (USP, SBP e APAE), perfazendo 23 referências. Entre os critérios de inclusão considerou-se o ano, de preferência nos últimos cinco anos, embora alguns trabalhos mais antigos tenham sido também utilizados, devido a sua autêntica importância ou devido à inexistência de versões mais atualizadas; presença de dois ou mais descritores; e acessibilidade do conteúdo, preteridos os artigos muito específicos ou com detalhamento excessivo.

Após análise dos periódicos, propôs-se a necessidade da criação de tecnologias de informação, a saber, boletim informativo em linguagem técnica, mas de fácil interpretação, e um fluxograma de atendimento na atenção básica, com ilustrações sobre o traço falciforme, a fim de orientar os profissionais atuantes na atenção básica na interpretação da triagem para hemoglobinopatias do teste do pezinho.

\section{REVISÃO DA LITERATURA}

\section{A molécula de hemoglobina, suas mutações e a patofisiologia da doença falciforme}

A molécula de hemoglobina é um tetrâmero formado por quatro cadeias proteicas unidas por grupamentos heme (quatro anéis de Protoporfirina, cada um com um átomo de ferro central), geralmente, duas cadeias tipo alfa e duas cadeias não-alfa tipo beta, gama ou delta. A principal função da hemoglobina é carrear o oxigênio dos pulmões, distribuindo-o aos tecidos, embora outras funções, como distribuição de óxido nítrico e regulação do tônus vasomotor também sejam referidos. ${ }^{4,6}$

Quando ocorre a troca do sexto aminoácido da cadeia beta, valina, pelo ácido glutâmico (GAG-GTG), ocorre a formação da Hemoglobina $S$, levando à formação de polímeros rígidos das cadeias de globina e precipitação destas, formando cordões fibrosos que geram a conformação 
eritróide falciforme, uma menor capacidade deformacional das hemácias e trombose da microcirculação. A polimerização envolve também proteínas da membrana e a conformação diferenciada das células falciformes acarreta aumento da concentração de hemoglobina e densidade das hemácias, afetando o equilíbrio hidroeletrolítico e gerando desidratação celular, principalmente quando há desoxigenação, ou em ambientes hipóxicos e ácidos. Além disso, as modificações na membrana, estrutural e funcionalmente, desordem no controle de volume celular e o aumento da aderência ao endotélio atuam em conjunto para o espectro sintomático da doença. ${ }^{6-8}$ Acredita-se que genes mutantes para a resposta inflamatória estejam associados com a mutação da $\mathrm{HbS}$, produzindo uma resposta inflamatória exacerbada. ${ }^{1,6}$

A Hemoglobina $\mathrm{F}$ é a hemoglobina predominante no feto. Produzida no fígado e no baço, a partir da $8^{\mathrm{a}}$ semana de vida intrauterina, esta hemoglobina possui maior afinidade pelo oxigênio, sendo mais resistente à desnaturação, e possui também função protetora, pois consegue diluir a hemoglobina $\mathrm{S}$ no meio intracelular, impedindo sua polimerização. Sua concentração se reduz até o término do primeiro ano de vida, protegendo o lactente dos efeitos deletérios da Hemoglobina S. ${ }^{7,9,10}$

Normalmente, na fase adulta, há três tipos de hemoglobina em circulação: Hemoglobina $\mathrm{A}(\mathrm{HbA})$, formada por duas cadeias alfa e duas cadeias beta, sendo a mais prevalente, cerca de $97 \%$; Hemoglobina A2 (HbA2), formada por duas cadeias alfa e duas cadeias delta, em menor quantidade, cerca de 2,5\%; e Hemoglobina $\mathrm{F}(\mathrm{HbF})$, ou Fetal, formada por duas cadeias alfa e duas cadeias gama, e a menos prevalente, cerca de menos de $1 \%$. $^{7,10}$

\section{A doença falciforme e o traço falciforme}

Doença falciforme engloba um grande aspecto de perfis falciformes que possuem clínica ou mesmo patofisiologia semelhantes. Os sintomas decorrem de fenômenos vasoclusivos e hemolíticos, mas podem ser bem variados dependendo do perfil genético ou de características pessoais (perfil epigenético). O início dos sintomas se dá após o sexto mês de vida, devido à mudança do perfil hemoglobínico, com redução da produção de Hemoglobina F. ${ }^{10,11}$

As crises álgicas são as manifestações vasoclusivas mais comuns e são o tipo de complicação que mais leva à emergência (até 30\% dos pacientes vão à emergência até seis vezes ao ano devido à dor aguda). As crises álgicas podem ser precipitadas por condições climáticas, desidratação, estresse, infecções, dentre outros, e a dor pode acometer qualquer parte do corpo, sendo comum a dactilite, dor torácica (síndrome torácica aguda), dor abdominal (isquemia mesentérica ou sequestro esplênico), priapismo, dor óssea por infarto ósseo e subsequente osteomielite por Salmonella, e eventos neurológicos, como acidente vascular encefálico isquêmico, cerca de $25 \%$ das crianças com anemia falciforme fazem lesões isquêmicas silenciosas que podem ocasionar danos à função neurocognitiva. ${ }^{11,12}$

Outra complicação muito comum e que é a principal causa de morbimortalidade na anemia falciforme é a ocorrência de infecções, devido à disfunção esplênica e à incapacidade deste de filtrar micro-organismos da corrente sanguínea, levando à sepse por bactérias encapsuladas; como Pneumococo, Meningococo e Hemofilus; e alguns vírus, sendo necessário início precoce de antibioticoprofilaxia com Penicilina V oral e vacinação específica. ${ }^{11-13}$

Traço falciforme não é considerado uma doença, é uma condição benigna de portador do gene mutante para $\mathrm{HbS}$, não necessitando de acompanhamento especializado, sendo, no entanto, essencial que os pais de crianças portadoras do traço falciforme recebam orientações gerais e de aconselhamento genético. No caso em que a criança portadora de traço falciforme (FAS), ou dos resultados FAC (hemoglobina F, hemoglobina A e hemoglobina $\mathrm{C}$ ) ou FAD (hemoglobina F, hemoglobina A e hemoglobina D) ou FAE (hemoglobina F, hemoglobina A e hemoglobina E), apresentar anemia, é recomendável excluir anemia ferropriva. Excluída ou tratada, caso permaneça a anemia, deve-se encaminhar para avaliação com hematologista e realização de eletroforese de hemoglobina. Embora usualmente assintomático, alguns estudos demonstram que possa estar associado raramente a alguns eventos tromboembólicos venosos em situações adversas ou após exercícios extenuantes, como hematúria, câncer renal (em casos muito raros), doença renal crônica, rabdomiólise e morte súbita. ${ }^{5,14}$

\section{Programa nacional de triagem neonatal e o diagnóstico da doença falciforme}

Os princípios gerais de um programa de triagem neonatal devem considerar que a triagem seja economicamente viável, de fácil realização, elevada precisão, voltada para doenças de fácil detecção, de alta prevalência e que não apresentem características clínicas precoces, em quais a intervenção possa alterar a história natural da doença, reduzindo assim sua morbimortalidade, dando acesso ao acompanhamento com brevidade ao especialista e à equipe multidisciplinar, disponibilizando as medicações excepcionais e realizando busca ativa dos casos suspeitos e confirmados. ${ }^{15}$

Entre o terceiro e o quinto dia, uma amostra é coletada e, de acordo com o tipo e a concentração das hemoglobinas encontradas, representadas cada uma por letras em ordem de prevalência, podem ser identificados os casos normais, os traços e os possíveis casos de doença falciforme. Diante de um resultado positivo, o recém-nascido deve ser encaminhado ao hematologista para realização de teste confirmatório e para pesquisa dos familiares. A partir do primeiro mês de vida, o padrão de resultados para o teste confirmatório sofre algumas mudanças, sendo necessário acompanhamento da idade na qual os exames foram colhidos, considerando-se que, por diversas razões, a consulta ou a coleta podem ter sido atrasadas, a saber, desinformação dos pais sobre os testes de triagem ou histórico familiar da doença, espera para conseguir encaminhamentos, atraso na liberação dos resultados pelos laboratórios responsáveis. ${ }^{5,16}$

\section{DISCUSSÃO}

Vários estudos já se propuseram a definir a prevalência de doença falciforme e traço falciforme no país, a tendência 
atual de melhoria das condições de vida sugere que cada vez mais crianças com estas condições chegam à fase adulta e reprodutiva, e, portanto, a prevalência tende a ser cada vez maior não só no país, mas em todo o mundo.

Um estudo transversal realizado em Pernambuco utilizou a base de dados estadual do teste do pezinho e realizou triagem familiar ampliada dos casos índices de doença falciforme identificados entre 2001 e 2005, tendo encontrado dentro da população estudada (21 casos índices e 463 familiares), 114 casos de traço falciforme, correspondente a $25 \%$ dos familiares. Destes, $81 \%$ desconheciam a condição, 53,3\% estavam em idade reprodutiva e $80 \%$ já haviam gerado filhos, o que gerou um incremento de casos de traço falcêmico e aumento da possibilidade de gerar crianças com anemia falciforme. ${ }^{17}$

No Paraná, o estudo conduzido entre os anos de 2002 a 2004, demonstrou uma prevalência para o traço falcêmico de 150/10.000 nascimentos. Em Ribeirão Preto, referência nacional em triagem neonatal, a prevalência foi de 1/37,5 mil nascidos vivos. Outro estudo transversal realizado no Distrito Federal, referentes aos dados do centro de referência em triagem neonatal, entre os anos de 2004 a 2006, demonstrou uma prevalência de 323/10.000 nascimentos para o traço falciforme e de 9/10.000 nascimentos para anemia falciforme, concluindo que a elevada prevalência deve ser considerada uma informação preciosa para ação de gestores no desenvolvimento de programas e ações educacionais sobre o traço falciforme e a doença falciforme..$^{15,18,19}$

No Ceará, um estudo conduzido na Maternidade Escola Assis Chateaubriand (MEAC) entre os anos de 2001 a 2002, com uma amostra de 389 recém-nascidos, encontrou prevalência de $3,8 \%$ das amostras positivas para traço falciforme, e $0,2 \%$ de anemia falciforme, sendo o único encontrado na literatura, realizado no estado. ${ }^{20}$

O estudo de prevalência nacional realizado em 2009, demonstrou a dispersão por estados dos casos de anemia falciforme e traço falciforme. Segundo este estudo, a prevalência na região sudeste, nos estados de São Paulo, Rio de Janeiro e Minas Gerais podem chegar a um caso para 1000 nascidos vivos com anemia falciforme e um caso a cada 27 nascimentos com traço falciforme. Crê-se que na população negra brasileira, de $1 \%$ a $6 \%$ possuem o traço falciforme, o que o configura como um sério problema de saúde pública. A Figura 1 demonstra a distribuição por estados encontrada neste estudo. ${ }^{4}$

Figura 1. Distribuição e prevalência de traço falcêmico e anemia falciforme no Brasil. ${ }^{4}$

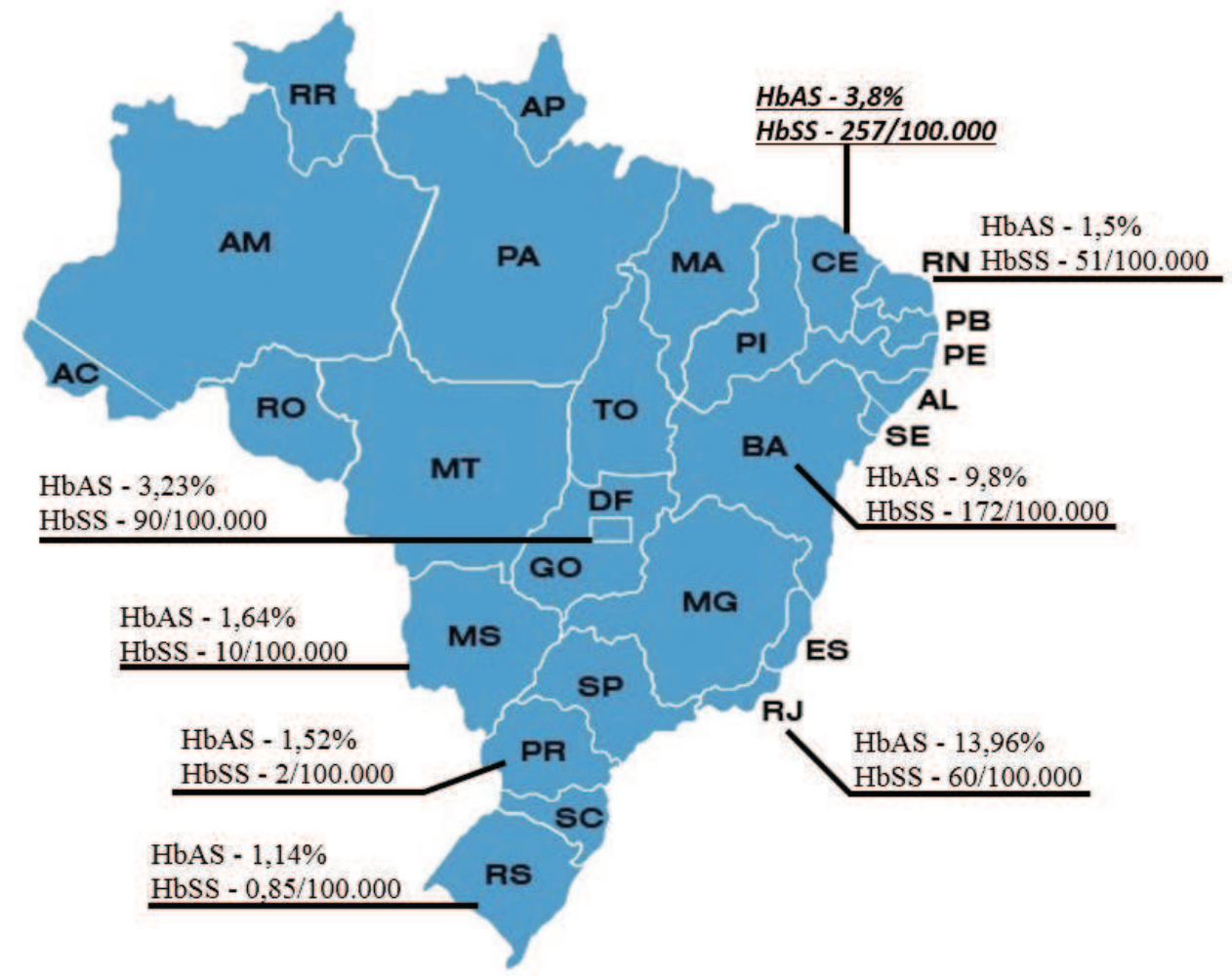

Diante da grande prevalência de casos de traço falciforme e anemia falciforme em nosso país, cabe ao profissional de atenção básica, médico e enfermeira, lidar com os resultados dos testes de triagem para hemoglobinopatias, devendo conduzir de forma que a criança e a família possam receber o melhor atendimento, orientações e acompanhamento necessários, encaminhando ao especialista quando necessário.

Um trabalho publicado em 2014 realizou questionários com médicos obstetras para conhecer o nível de conhecimento 
sobre anemia falciforme, traço falciforme, cuidados com gestantes portadoras de doença falciforme e aconselhamento genético pré-natal. Como resultado foi verificado que existiam diferenças entre os guidelines para acompanhamento e o tipo de aconselhamento dado a estas pacientes, provando ser necessário um maior enfoque sobre o tema, na educação médica. ${ }^{21}$

Nos EUA, no estado de Massachusetts, como no Brasil, o resultado do teste do pezinho é primeiramente avaliado pelo médico da atenção primária, e em algumas situações, ocorrem encaminhamentos imprecisos ao hematologista. Então, foi realizada uma pesquisa intervencionista para avaliar o conhecimento dos profissionais de atenção básica, médicos generalistas, enfermeiros e pediatras, e o incremento do conhecimento sobre anemia e traço falciformes através de dois diferentes métodos educativos, seminários e material escrito. O estudo não encontrou diferenças entre os métodos, mas provou que o conhecimento e a confiança na condução destes casos na atenção primária podem aumentar de maneira significativa com estratégias educacionais simples. ${ }^{22}$

Uma pesquisa utilizando um questionário pré-estruturado baseado no Manual do Ministério da Saúde foi utilizado no município de Montes Claros, no interior de Minas Gerais, com o intuito de avaliar os conhecimentos dos profissionais de atenção básica, médicos e enfermeiros, sobre a epidemiologia, manifestações clínicas e conduta frente às crianças com

Figura 2. Boletim informativo sobre traço falciforme página 1.

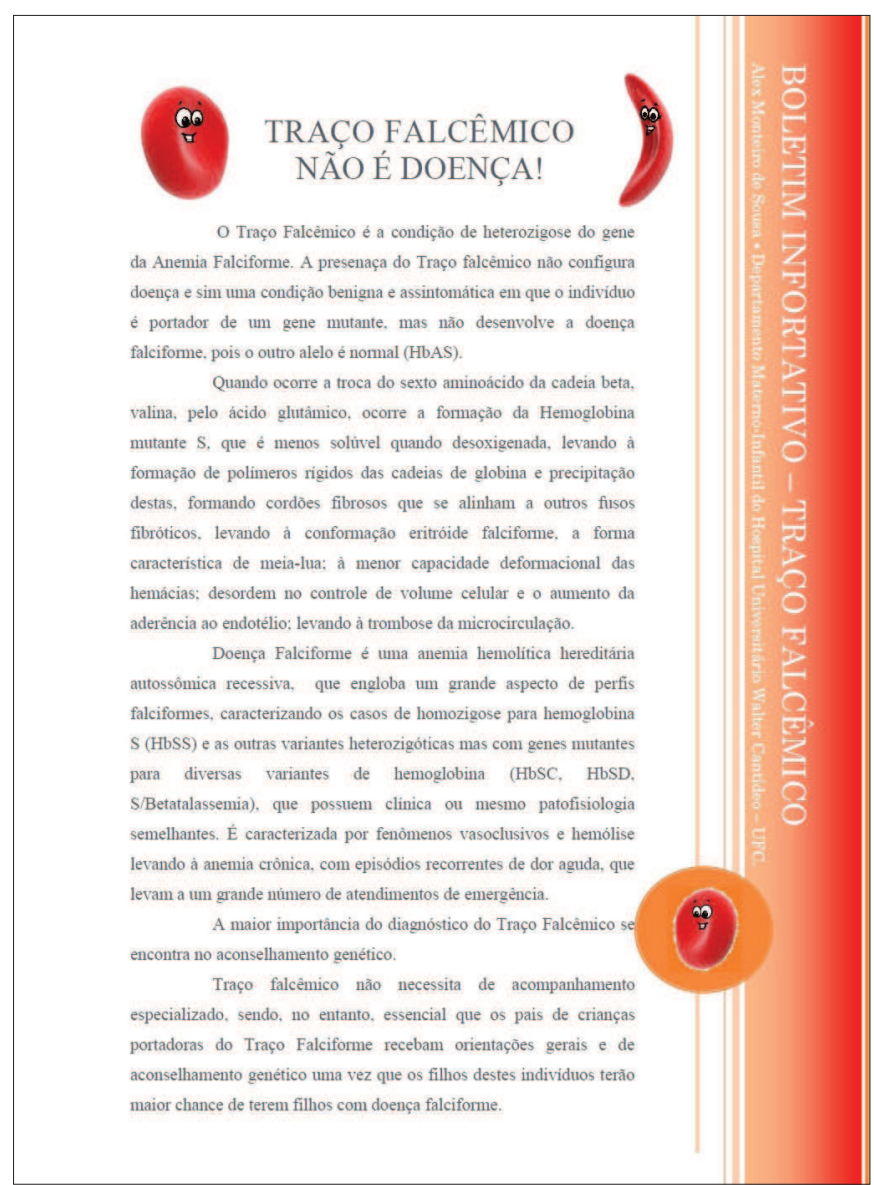

doença falciforme. O nível de conhecimento foi relacionado à qualidade de atenção prestada. Todas as três pontuações não alcançaram $75 \%$ de aproveitamento, demonstrando níveis abaixo do desejado, o que poderia comprometer os cuidados com estes pacientes, a busca ativa de familiares e identificação dos casos. ${ }^{23}$

\section{CONSIDERAÇÕES FINAIS}

Diante da alta prevalência de traço falciforme no país, faz-se necessária uma boa base de conhecimentos sobre a interpretação da triagem para hemoglobinopatias do teste do pezinho, sobre a epidemiologia, sinais clínicos e condutas frente à criança com doença ou traço falciforme para os profissionais da atenção primária, visando a promoção de saúde e melhora da qualidade de vida, além de evitar a oneração do sistema de saúde. A orientação destes profissionais pode ser realizada através de diversas estratégias educacionais.

Diante dos dados discutidos, propõe-se a criação e divulgação de um boletim informativo (Figura 2 e 3) e fluxograma (Figura 4) sobre traço, visando a orientação dos profissionais atuantes na atenção primária na interpretação da triagem para hemoglobinopatias, deste modo, provendo um cuidado longitudinal com abordagem familiar multiprofissional para os pacientes com doença falciforme e provendo aconselhamento genético e acompanhamento na atenção básica dos pacientes com traço falciforme.

Figura 3. Boletim informativo sobre traço falciforme página 2.

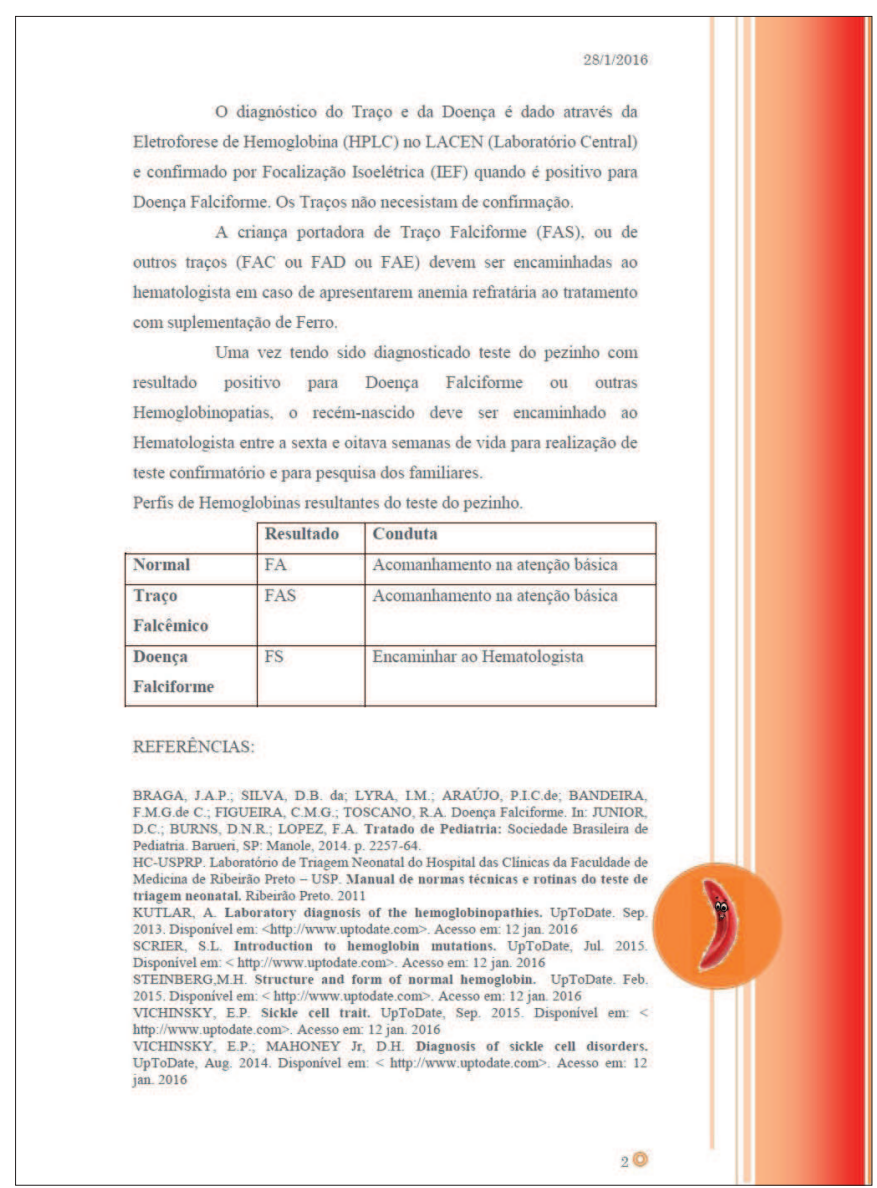


Figura 4. Fluxograma de atendimento e conduta do paciente com traço falciforme na atenção primária.

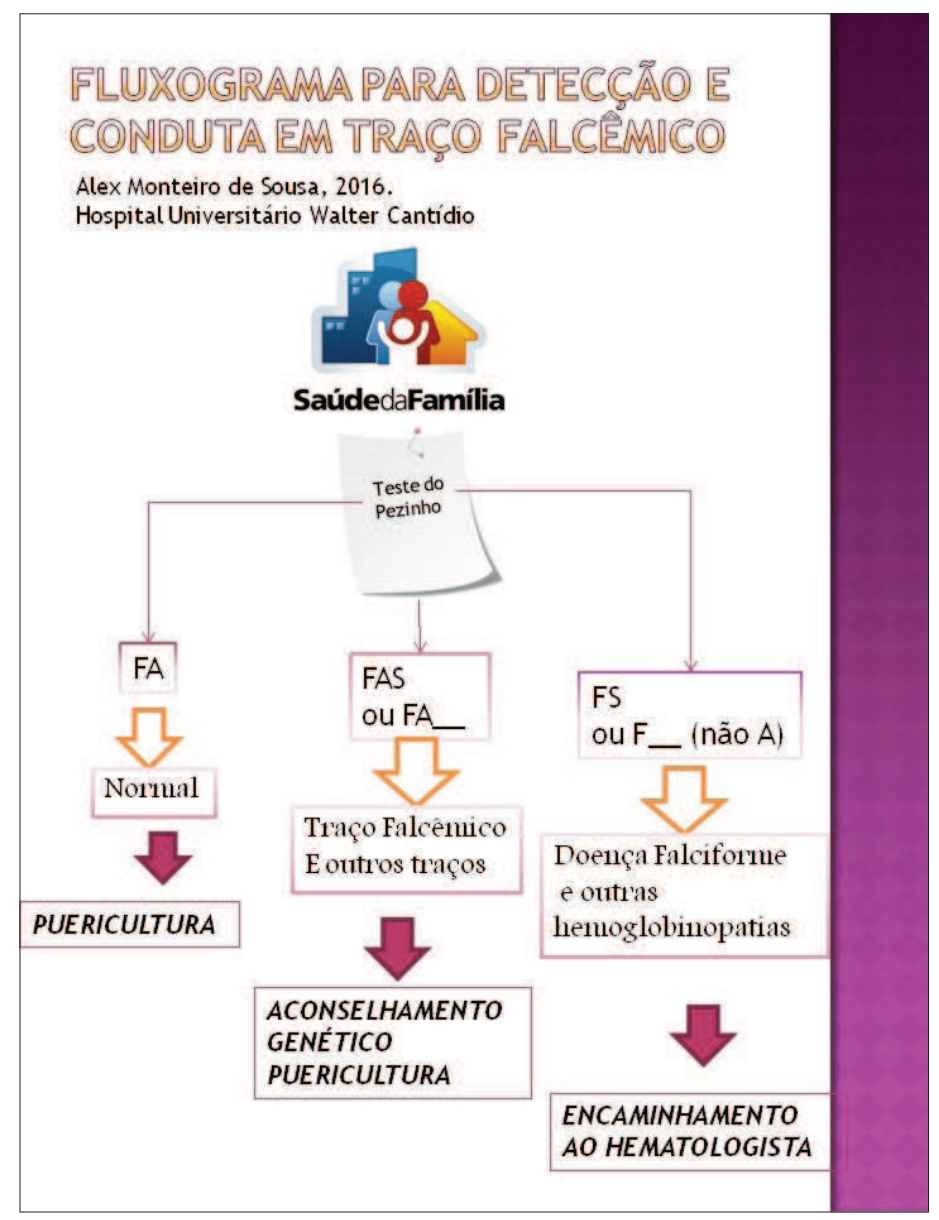

\section{REFERÊNCIAS}

1. Braga JA, Silva DB, Lyra IM, Araújo PI, Bandeira FM, Figueira $\mathrm{CM}$, et al. Doença Falciforme. In: Campos D Junior, Burns DN, Lopez FA. Tratado de Pediatria: Sociedade Brasileira de Pediatria. Barueri, SP: Manole; 2014. p. 2257-2264.

2. Vichinsky EP, Mahoney DH Júnior. Diagnosis of sickle cell disorders [Internet]. [s.1.]: UpToDate; 2014 [acesso em: 12 jan 2016]. Disponível em: http://www.uptodate.com/contents/diagnosis-ofsickle-cell-disorders?source $=$ search $\_$result\&search $=$sickle + cell + dise ase \&selectedTitle $=6 \sim 150$

3. Vichinsky EP. Sickle cell trait [Internet]. [s.1.]: UpToDate; 2015 [acesso em: 12 jan 2016]. Disponível em: http://www.uptodate.com/ contents/sickle-cell-trait?source $=$ search_result\&search $=$ sickle + cell + trait\&selectedTitle $=1 \sim 100$

4. Lervolino LC, Baldin PE, Picado SM, Viel AA, Campos LA. Prevalence of sickle cell disease and sickle cell trait in national neonatal screening studies. Rev Bras Hematol Hemoter. 2011;33(1):49-54.

5. Laboratório de Triagem Neonatal do Hospital das Clínicas da Faculdade de Medicina de Ribeirão Preto. Manual de normas técnicas e rotinas do teste de triagem neonatal [Internet]. Ribeirão Preto: HC-USPRP; 2011. [acesso em: 12 jan 2016]. Disponível em: http://www.hcrp.usp.br/sitehc/upload\%5CMANUAL\%20DE\%20 INSTRU $\%$ C3\%87\%C3\%95ES\%20DO $\% 20$ TESTE $\% 20 D O \% 20$ PEZINHO\%202011.pdf
6. Steinberg MH. Structure and form of normal hemoglobin [Internet]. [s.l.]: UpToDate; 2015 [acesso em: 12 jan 2016]. Disponível em: http://www.uptodate.com/contents/structure-and-function-ofnormal-hemoglobins?source=search_result\&search=normal + hemog lobin\&selectedTitle $=3 \sim 150$

7. Kutlar A. Laboratory diagnosis of the hemoglobinopathies [Internet]. [s.l.]: UpToDate; 2013 [acesso em: 12 jan 2016]. Disponível em: http://www.uptodate.com/contents/laboratorydiagnosis-of-the-hemoglobinopathies?source=search_result\&search $=$ hemoglobinopathies\&selectedTitle $=1 \sim 150$

8. Vichinsky EP. Clinical variability in sickle cell anemia [Internet]. [s.1.]: UpToDate; 2014 [acesso em: 12 jan 2016]. Disponível em: http://www.uptodate.com/contents/clinical-variability-in-sickle-cellanemia? source $=$ search_result\&search $=$ sickle + cell + anemia\&selecte $\mathrm{dTitle}=6 \sim 150$

9. Scrier SL. Introduction to hemoglobin mutations [Internet]. [s.l.]: UpToDate; 2015 [acesso em: 12 jan 2016]. Disponível em: http://www.uptodate.com/contents/introduction-to-hemoglobinmutations? source $=$ search result\&search $=$ hemoglobin + mutations\&s electedTitle $=2 \sim 150$

10. Steinberg MH, Thein SL, Path FR. Fetal hemoglobin (hemoglobin F) in health and disease [Internet]. [s.1.]: UpToDate; 2015 [acesso em: 12 jan 2016]. Disponível em: http://www. uptodate.com/contents/fetal-hemoglobin-hemoglobin-f-in-health- 
and-disease ?source $=$ search result\&search $=$ fetal + hemoglobin\&sele ctedTitle $=1 \sim 76$

11. Vichinsky EP. Overview of the clinical manifestations of sickle cell disease [Internet]. [s.1.]: UpToDate; 2015 [acesso em: 12 jan 2016]. Disponível em: http://www.uptodate.com/contents/overviewof-the-clinical-manifestations-of-sickle-cell-disease?source=search result\&search $=$ sickle + cell + disease $\&$ selectedTitle $=3 \sim 150$

12. Rogers ZR. Routine comprehensive care for children with sickle cell disease [Internet]. [s.1.]: UpToDate; 2015 [acesso em: 12 jan 2016]. Disponível em: http://www.uptodate.com/contents/ routine-comprehensive-care-for-children-with-sickle-celldisease ? source $=$ search_result\&search $=$ sickle + cell + disease $\&$ selecte dTitle $=15 \sim 150$

13. Field JJ, Vichinsky EP, Debraun MR. Overview of management and prognosis of sickle cell disease. [Internet]. [s.1.]: UpToDate; 2015 [acesso em: 12 jan 2016]. Disponível em: http://www.uptodate.com/ contents/overview-of-the-management-and-prognosis-of-sicklecell-disease ?source $=$ search_result\&search $=$ sickle + cell + disease $\&$ sel ectedTitle $=2 \sim 150$

14. Key NS, Connes P, Derebail VK. Negative health implications of sickle cell trait in high income countries: from the football field to the laboratory. Br J Haematol. 2015;170(1):5-14.

15. Diniz D, Guedes C, Barbosa L, Tauil PL, Magalhães I. Prevalência do traço e da anemia falciforme em recém-nascidos do Distrito Federal, Brasil, 2004 a 2006. Cad Saúde Pública. 2009;25(1):188-94.

16. Associação de Pais e Amigos dos Excepcionais - APAE. Teste do Pezinho: manual de instruções. [Internet]. São Paulo: APAE; 2014 [acesso em: 12 jan. 2016]. Disponível em: http://autapaesp.org.br/ptbr/teste-do-pezinho/profissionais-de-saude/Documents/manual $\% 20$ instrucoes-eletr\%C3\%B4nico_novembro2014.pdf
17. Bandeira FM, Santos MN, Bezerra MA, Gomes YM, Araújo AS, Braga MC, et al. Triagem familiar para o gene HbBS e detecção de novos casos de doença falciforme em Pernambuco. Rev Saúde Pública. 2008;42(2);234-41.

18. Watanabe AM, Pianovsky MA, Zanis J Neto, Lichtvan LC, Chautard-Freire-Maia EA, Domingos MT, et al. Prevalência da hemoglobina S no estado do Paraná, Brasil, obtida pela triagem neonatal. Cad Saúde Pública. 2008;4(5):993-1000.

19. Magalhães PK, Turcato MF, Ângulo IL, Maciel LM. Programa de triagem neonatal da Faculdade de Medicina de Ribeirão Preto, Universidade de São Paulo, Brasil. Cad Saúde Pública. 2009;25(2):445-54.

20. Pinheiro LS, Gonçalvez RP, Tomé CA, Alcântara AE, Marques AR, Silva MM. Prevalência de hemoglobina S em recém-nascidos de Fortaleza: importância da investigação neonatal. Rev Bras Ginecol Obstet. 2006;28(2):122-5.

21. Azonobi IC, Anderson DL, Byans VN, Grant AM, Schulkin J. Obstetrician-Gynecologists' knowledge of sickle cell disease screening and management. BMC Pregnancy and Childbirth. 2014;14(356):1-5.

22. Oyeku SO, Feldman HA, Ryan K, Muret-Wagstaff S, Neufeld EJ. Primary care clinicians' knowledge and confidence about newborn screening for sickle cell disease: randomized assessment of educational strategies. J Natl Med Assoc. 2010;102(8):676-82.

23. Gomes LM, Vieira MM, Reis TC, Barbosa TL, Caldeira AP. Knowledge of family health program practitioners in Brazil about sickle cell disease: a descriptive, cross-sectional study. BMC Family Practice. 2011;12(89):1-7.

\section{Como citar:}

Sousa, AM, Silva FR. Traço falciforme no Brasil: revisão da literatura e proposta de tecnologia de informação para orientação de profissionais da atenção primária. Rev Med UFC. 2017 mai-ago;57(2):37-43. 